\title{
Research on the Construction of Intelligent Logistics Information System
}

\author{
Jing Li \\ Shandong Xiehe University, Jinan, Shandong, 250107, China
}

Keywords: Intelligent Logistics, Information System, Logistics Information Technology.

\begin{abstract}
This paper analyzes the requirements of intelligent logistics information system, and analyzes the overall goal, system framework, characteristics, basic functions and expansion functions of intelligent logistics information system. Finally, it analyzes and summarizes the key technologies of intelligent logistics information system to promote the construction of intelligent logistics information system.
\end{abstract}

\section{Introduction}

Based on big data and related technologies, intelligent logistics has great advantages in improving logistics efficiency, reducing logistics costs and improving user experience satisfaction, so it represents the development direction of logistics mode.

Intelligent logistics information platform supports the efficient operation of intelligent logistics. The platform integrates all kinds of logistics information and resources, uses advanced information technology and intelligent technology, integrates supply chain logistics, and intelligently solves logistics problems. The intelligent logistics information platform is helpful to solve the problems of repeated construction, information isolation and lack of intelligent function of the main information platform of logistics business. By integrating all kinds of logistics information and resources and integrating the application of artificial intelligence technology, the intelligent logistics information platform can provide efficient, low-cost and integrated logistics services and promote the development of local economy.

\section{Demand Analysis of Intelligent Logistics Information System}

\subsection{Intelligent Logistics}

Logistics intelligence is the application of logistics automation, information, network and other aspects at a higher level. With the fierce competitive environment of logistics and the development of science and technology, the high standard of customers' demand for logistics service of enterprises, enterprises need to optimize the resources of the whole system and realize the maximization of management efficiency in order to enhance their own competitive advantage, such as how to realize the control of safety stock, how to optimize the transportation path, how to select the location of logistics center, etc., so as to promote The enterprise introduces the intelligent logistics information system to realize the intelligence of the whole logistics process, so that the enterprise can fully allocate the internal and external resources of the enterprise, realize the intelligence of the management process, provide value-added logistics services for customers with higher quality, and realize the greater development of the enterprise itself. Therefore, the realization of the intelligence of logistics is the inevitable requirement of the development of intelligent logistics information system.

\subsection{Logistics Integration}

Logistics integration refers to the integration and optimization of various resources in the logistics information system in order to achieve the maximum utilization of system resources and effectively reduce related costs. On the one hand, in terms of the internal logistics information system, it is necessary to realize the integration of logistics facilities and equipment, logistics information data collection, logistics information processing and other technical levels, as well as 
the integration of the functions of each subsystem of the logistics information system, so as to maximize the internal functions of the information system to a greater extent; on the other hand, in terms of the management of the whole logistics supply chain, enterprises should be smooth To develop business, we need to realize the integration of logistics information system and other systems, realize the transparency of supply chain management, and enable the main body of the supply chain to obtain logistics information timely and accurately. In order to achieve effective management of the supply chain, different supply chain entities need to fully share information with each other, and intelligent logistics information system integration and integration of system resources are needed to achieve integrated management of the whole supply chain.

\subsection{High End Logistics}

Compared with traditional logistics, high-end logistics has significant advantages in technology content, types of additional services, timeliness of services, high-quality service personnel, etc. For enterprises, the ultimate goal of enterprise management is to reduce the logistics cost, excavate the logistics value to maximize the logistics profit. High-end logistics service has become the ultimate goal of intelligent logistics information system to provide logistics service. The high-end logistics service requires high quality and ability. The realization of high-end logistics service needs the support of logistics information technology represented by the Internet of things and the deep integration of logistics information, so as to integrate the resources in the system to a greater extent, provide various value-added logistics services and realize the high-end logistics development, which is the future development demand of intelligent logistics information system.

\subsection{Low Carbon Logistics}

In recent years, environmental pollution and the development of clean resources have become the bottleneck of economic development. A low-carbon economic model aimed at reducing carbon dioxide emissions has attracted more and more attention. The development of low-carbon economy can not be separated from the influence of various potential factors. In the development process of logistics information system, it should also meet the development requirements of low-carbon economy, so low-carbon logistics has emerged. Low carbon, as the name implies, is to reduce carbon dioxide emissions. Enterprises can realize low-carbon economy in the process of actual production or service provision. For example, if logistics enterprises install Baidou satellite positioning system for transportation vehicles, they can optimize transportation routes and reduce carbon emissions; they can use transportation vehicles or other facilities and equipment with low carbon emissions. All these logistics activities can not be realized without the effective processing of various information by information system. Therefore, the promotion of low-carbon economy objectively promotes the actual demand for intelligent logistics information system.

\subsection{Mobile Platform Services}

The popularization and application of mobile Internet and smart phones put forward higher requirements for convenient platform service. Through the intelligent terminal equipment, users hope to release the demand information and logistics services at any time on the platform, and query the logistics link and status of goods on the platform in time, so as to realize the tracking and positioning of vehicles and personnel. This requires the platform and related network station, client, mobile app and other channels to achieve interoperability and interaction.

\section{Analysis of Elements and Structure of Intelligent Logistics Information System}

\subsection{Overall Objective of Intelligent Logistics Information System}

The effective management of intelligent information needs intelligent logistics information system as the basis of management, and the essence of intelligent logistics information system is the control of goods or services from the beginning to the end. The overall goal of intelligent logistics information system is to realize the effective processing of information inside and outside the system, realize the intelligent management of processes, bring greater benefits to system users and 
customers, and then improve the integration level of logistics services, more accurately manage logistics activities and provide logistics services in a dynamic way.

\subsection{System Framework of Intelligent Logistics Information System}

Intelligent logistics information system is a higher-level development of traditional logistics information system. It is to meet the needs of all parties to the greatest extent, play the role of intelligent technology to realize the function of information system, and form the internal and external management level, so as to provide decision support for the business management activities of enterprises. To some extent, intelligent logistics information system is similar to human brain center, which controls the whole logistics management and business process. The system framework of intelligent logistics information system describes the process of logistics activities and the relationship between various elements. The system structure of intelligent logistics information system can be explained from eight aspects, including key technology, logistics public information platform, management, realizable function, external gate station of the system, etc.

\subsection{Characteristic Analysis of Intelligent Logistics Information System}

An outstanding feature of intelligent logistics information system is the application of intelligent technology, so as to realize the intelligent management of the whole logistics process, so as to better improve the management decision-making level of enterprises and the corresponding logistics efficiency. Intelligent logistics information system has its own characteristics in the specific application process, mainly in the following aspects:

(1) Take information movement as the main line. The core element of intelligent logistics information system is information. Intelligent logistics information system is to realize the flow of information flow without dead angle by using intelligent technology, to maximize the value of information, and to provide maximum benefits for system users by using information sharing.

(2) To meet the needs of customers. The realization of intelligent logistics information system mainly depends on electronic operation.

\subsection{Function Division of Intelligent Logistics Information System}

(1) Data collection and input. There is a lot of information in the process of management and business operation of intelligent logistics information system. Through intelligent technology to collect all kinds of information, system managers, customers, etc. can complete the input of business activity data through the system application interface.

(2) Data transmission. Intelligent logistics information system uses Internet technology to transmit data quickly and conveniently across regions and time periods, which can greatly improve the efficiency and timeliness of data transmission in logistics management activities.

(3) Data processing. Intelligent logistics information system through the statistical analysis of the collected information data, find out the actual significance of the data, and provide reference for the decision-making and prediction of logistics activities. In addition, the intelligent logistics information system uses the integration of various information technologies to conduct deep data mining, process into database, and form information resources.

(4) Data storage. The application of cloud platform technology promotes the realization of cloud storage function. In the intelligent logistics information system, there are various forms of databases, which store data in different categories, so that users can quickly call and provide information sources for decision-making.

(5) Data output. With the application of intelligent technology, the upgrade of intelligent logistics information system function, the data processing results show a variety of changes, such as $3 \mathrm{D}$ charts, which can more intuitively reflect the actual value implied by the data.

(6) Control function. The control of the system is not simply the management of people and things. The control of intelligent logistics information system is the management of logistics information to reduce the distortion of information and more accurately reflect the logistics activities.

(1) Intelligent distribution function. Intelligent logistics information system uses intelligent 
distribution technology to select the best transportation path by analyzing various resources inside and outside the system and the needs of all parties, so as to reduce the distribution cost and manage the logistics activities.

(2) Cargo tracking function. Baidou satellite navigation system is used to track the status and location of goods in real time, and data warehouse and data mining technology are used to process data, so that users can monitor the transportation vehicles, goods routes and conditions in real time.

(3) Inventory management function. Through the integration of the information platform resources of intelligent logistics information system, on the premise of meeting the needs of users, historical data are analyzed, and factors such as customer service level and transportation cost are considered to maintain the lowest inventory level.

(4) Decision analysis function. The intelligent logistics information system uses the system function to establish the mathematical analysis model, import the data into the mathematical model, and obtain the logistics strategy and strategic options, logistics center location, logistics management strategy, etc., so as to provide the most reasonable decision-making scheme for enterprise managers.

(5) Financial services function. With the improvement of the national financial security policy and the diversification of financial service institutions, intelligent logistics information system integrates the relevant services of financial institutions to add financial services for customers.

\section{Key Technology Analysis of Intelligent Logistics Information System}

The effective development of intelligent logistics information system is inseparable from the support of intelligent information technology. The application of intelligent logistics information technology can well realize the real-time control of vehicles and goods, so as to reduce the logistics cost and improve the logistics efficiency. Intelligent logistics information system not only uses multi-functional handheld, RFID fixed reader, GPS and other technologies to obtain information, but also transports the collected information to the logistics information center through the network, and the logistics information center makes judgment and control, and makes real-time adjustment. In essence, intelligent logistics information system is a process of information collection, processing, transmission and utilization. The relationship between intelligent logistics information system and intelligent technology.

\subsection{Automatic Identification Technology}

The generation and development of automatic identification technology has experienced a long historical period, and it has been very mature since 1970s. With the emergence and development of new science and technology, the types and functions of automatic identification technology have been greatly improved, but in essence, automatic identification technology is based on the development of computer, communication and other technologies. Automatic identification technology is widely used in warehousing, transportation, packaging, distribution and other logistics links. Now automatic identification technology has developed into a comprehensive system technology of various industries.

Bar code technology is simple, convenient and easy to operate in specific use. It has a wide range of application fields, ranging from the use of supermarket commodity packaging to the application of bar code technology in every link of logistics activities. For example, the problem of food safety, which attracts people's attention, can be easily solved by using barcode technology. By using barcode to query the source of food goods, the whole process of food production and transportation can be transparent, so as to ultimately have a positive impact on the overall market.

The principle of RFID technology is similar to bar code technology, which basically uses modern information tools to identify labels to obtain information. In logistics activities, RFID technology is widely used. For example, in the process of automobile processing and assembly, different parts are marked with specific labels, and RFID technology is used to control the purchase, transportation, consumption and other links of parts, so as to realize the transparent management of parts. 
Biometric technology is a kind of technology that uses human physiological or behavioral characteristics to identify identity. It mainly includes palm geometry recognition, gene recognition, vein recognition, gait recognition and so on. With the progress of science and technology, more and more biotechnologies have been applied in real life.

\subsection{Mobile Communication Technology}

The emergence and development of mobile communication technology has strengthened interpersonal communication to a large extent. With the in-depth development of economy and the actual development needs of enterprises, mobile communication technology has gradually been applied to the business field. The application of mobile communication technology depends on special mobile communication equipment. Information users can query and use relevant information conveniently by mobile communication equipment. For enterprises, the application of mobile communication technology can provide reference for the overall decision-making activities, better meet the needs of customers, and realize the electronization and networking of enterprise information management. Nowadays, the mobile communication technology has developed to the fourth generation, which has great advantages in the operation speed and download speed of the network. The fourth generation mobile communication technology makes the mobile communication network become a real information highway. The market environment is complex and changeable, and the arrival of big data era, how to tap the needs of potential customers to a greater extent has become a severe challenge for the long-term development of enterprises, and also a rare opportunity for enterprises. In today's era, whoever can timely understand the information or has strong information sensitivity can take the initiative in the increasingly fierce market competition. In this trend, the operation of intelligent logistics information system needs to use 4G mobile network technology, integrate logistics resource information, form a logistics industry portal site that meets the needs of both the supply and demand of the logistics industry, and realize fast logistics Service.

\subsection{Intelligent Transportation Technology}

In the intelligent logistics and intelligent logistics information system, intelligent transportation technology is mainly developed from three aspects:

In the field of intelligent transportation, mobile information technology is simply to make full use of the real-time monitoring and acquisition of information about transportation vehicles by positioning systems such as Beidou satellite system, and coordinate the scheduling of vehicles by relevant enterprises involved in the system, so as to maximize the use of vehicle information, reduce the no-load rate of vehicles, master the vehicle conditions, and ensure the safety of people and trucks. The Beidou satellite system is used to monitor the status of vehicles in real time. The application of vehicle positioning technology is convenient for controlling the status of vehicles, dispatching vehicles flexibly, optimizing the transportation path and ensuring the safety of goods, which can greatly improve the advantages of enterprises. With the help of the electronic identification system, we can track the goods in transit with specific information, accurately predict the arrival time, reasonably arrange the production, and effectively monitor the logistics activities.

\subsection{Data Warehouse And Data Mining Technology}

With the development of computer and related science and technology, the complexity and tediousness of logistics activities, there are various kinds of information in the development process of logistics. In order to better improve the scientific level of enterprise decision-making and improve the competitive advantage of the enterprise, we have to extract useful information from massive data for the enterprise, so as to improve the decision-making and development planning of the enterprise On the other hand, the arrival of the era of big data makes it difficult for enterprises to analyze useful information from a large number of data in a simple and accurate way. In order to obtain more convenient information, it has given birth to the demand of related data storage and data processing technology. In the mid-1980s, data warehouse, data mining and other data processing technologies came into being. With the further development of computer technology and 
mathematics, we can use mathematical knowledge and computer technology to mine big data and useful information. Generally speaking, data warehouse provides data sources for data mining through simple classification and processing of logistics information data, while constantly optimizing data and improving data. Data mining technology is to deal with some basic data, to deeply mine the actual meaning of the data, so as to provide the basis for the decision-making of enterprises. Nowadays, data warehouse and data mining technology play an increasingly important role in the era of big data.

\subsection{Cloud Platform Technology}

Cloud platform technology is generated on the basis of the development of Internet of things technology. Cloud platform technology is also composed of software and hardware, that is, cloud service software, computers and related accessories that load cloud platform clients. At present, cloud platform technology has been applied to the business process and daily management of intelligent logistics information system, and its technical advantages have been recognized by users. Cloud platform technology is widely used in the construction process of all kinds of cloud platforms, such as cloud storage platform, cloud marketing platform, cloud information platform, etc., for enterprises, to meet the needs of customers to the greatest extent is the survival way of enterprises, so it is inevitable to carry out enterprise publicity and product marketing in the development process of enterprises. Cloud marketing platform can To gather the needs of customers to the greatest extent, analyze the characteristics of customers and the characteristics of the enterprise itself, combined with the integration of cloud marketing platform, to provide a comprehensive and economic feasibility scheme as far as possible, so as to promote the convenience and science of the whole management process. Intelligent logistics information system, a platform for information exchange and cooperation, is more open and diversified due to the application of cloud platform technology.

\section{Conclusion}

The intelligent logistics information platform takes big data and Internet of things technology as the core support, integrates cloud computing, mobile Internet, artificial intelligence and other technologies, and provides relevant users with process visible, dynamic tracking and integrated intelligent logistics services. On this shared information platform, relevant subjects can realize realtime data exchange and information sharing, which greatly improves the efficiency of logistics integration of upstream and downstream enterprises in the supply chain and promotes the development of local economy.

\section{Acknowledgements}

This paper is the stage achievement of Shandong Social Science Planning and Cultivation Project in 2019: Shandong Intelligent Logistics Information System and its economic evaluation research, project number: 19CPYJ94.

This paper is the stage achievement of Shandong Xiehe Project in 2019: Shandong Intelligent Logistics Information System and its economic evaluation research, project number: XHXY201811

\section{Reference}

[1] Ya, Bing., Jiao. Based on the Electronic Commerce Environment ofIntelligent Logistics System Construction. Advanced Materials Researe, no. 850-851, pp. 1057-1060, 2014.

[2] Zhen, Liu., Xiao, Wang., Xiaoqin, Ma. Building intelligent logistics system based on Internet of things RFID in platform of cloud computing.Journal of Chemical\&Pharmaceutical Research, vol. 6, no. 6, pp. 772-778, 2014. 